\title{
Clinical chronobiology: a timely consideration in critical care medicine
}

\author{
Helen McKenna', Gijsbertus T. J. van der Horst ${ }^{2}$, Irwin Reiss ${ }^{3}$ and Daniel Martin ${ }^{1,3,4^{*}}$ (D)
}

\begin{abstract}
A fundamental aspect of human physiology is its cyclical nature over a 24-h period, a feature conserved across most life on Earth. Organisms compartmentalise processes with respect to time in order to promote survival, in a manner that mirrors the rotation of the planet and accompanying diurnal cycles of light and darkness. The influence of circadian rhythms can no longer be overlooked in clinical settings; this review provides intensivists with an up-to-date understanding of the burgeoning field of chronobiology, and suggests ways to incorporate these concepts into daily practice to improve patient outcomes. We outline the function of molecular clocks in remote tissues, which adjust cellular and global physiological function according to the time of day, and the potential clinical advantages to keeping in time with them. We highlight the consequences of "chronopathology", when this harmony is lost, and the risk factors for this condition in critically ill patients. We introduce the concept of "chronofitness" as a new target in the treatment of critical illness: preserving the internal synchronisation of clocks in different tissues, as well as external synchronisation with the environment. We describe methods for monitoring circadian rhythms in a clinical setting, and how this technology may be used for identifying optimal time windows for interventions, or to alert the physician to a critical deterioration of circadian rhythmicity. We suggest a chronobiological approach to critical illness, involving multicomponent strategies to promote chronofitness (chronobundles), and further investment in the development of personalised, time-based treatment for critically ill patients.
\end{abstract}

Keywords: Circadian rhythm, Chronobiology, Chronotherapy, Critical illness, Intensive care units

\section{Background}

Critical care medicine aims to maintain homeostasis in patients undergoing extreme physiological stress, for which they are no longer able to compensate. To this end, we strive to maintain physiological measures within parameters that we hope will promote optimal cell function and lead to survival; refining our targets as new evidence emerges. However, one fundamental facet of life has failed to form part of our concept of a patient's well-being: the innate rhythmicity of their biological functions. We are all instinctively aware of the diurnal nature of our own behaviour throughout a 24-h period. We recognise the physical and mental affliction associated with its disturbance (e.g. jet lag and night shift work), but we give little consideration to the

\footnotetext{
* Correspondence: daniel.martin@ucl.ac.uk

'University College London Centre for Altitude Space and Extreme

Environment Medicine, University College London Hospitals NIHR Biomedical

Research Centre, Institute of Sport and Exercise Health, First Floor, 170

Tottenham Court Road, London W1T 7HA, UK

${ }^{3}$ Division of Neonatology, Department of Paediatrics, Erasmus Medical

Center, Rotterdam, the Netherlands

Full list of author information is available at the end of the article
}

impact of these rhythms on the patients we treat. Most biological mechanisms fluctuate according to a circadian rhythm. The conservation of circadian rhythms across species points towards the survival advantage they convey, including: preparing an organism for daily recurring, and thus predictable, demands, such as the cyclical environmental changes in light, temperature and food availability imposed by the day-night cycle; and temporally segregating conflicting processes, such as feeding and physical activity, or sleeping and waking. The study of these cyclical phenomena, known as chronobiology, is growing in prominence throughout diverse disciplines, as their pervasive nature becomes apparent. During the extreme stress of critical illness, patients are particularly vulnerable from further impairment of cell function resulting from circadian rhythm disturbance. Critical care traditionally focuses on the "normalisation" of physiological indices, despite a limited evidence base $[1,2]$, but preservation of circadian physiology is not part of clinical practice. It is possible that neglecting the influence of circadian rhythmicity could contribute to the apparent lack of benefit

(C) The Author(s). 2018 Open Access This article is distributed under the terms of the Creative Commons Attribution 4.0 International License (http://creativecommons.org/licenses/by/4.0/), which permits unrestricted use, distribution, and 
from the majority of critical care targets tested in randomised controlled trials. In this review we introduce the basics of clinical chronobiology and propose the potential value to be gained from clinicians applying these new concepts to their daily practice. We propose that promotion of healthy circadian rhythms may constitute a future target for critical care medicine.

\section{The molecular networking of circadian rhythms}

Our planet rotates through $360^{\circ}$ every $24 \mathrm{~h}$, creating an inescapable oscillation between light and darkness. Most life on Earth evolved under the influence of this day-night cycle, leading to the parallel oscillation of behaviour, physiology and metabolism throughout the 24-h period (diurnal rhythms). These rhythms are generated by cell-intrinsic molecular clocks with a periodicity of approximately (circa) $24 \mathrm{~h}$ (diem), for which reason they are called "circadian" clocks. Temporal compartmentalisation of functions according to predictable daily fluctuations in the environment has been vital to the survival of even the most primitive organisms, such as the single-celled Synechococcus cyanobacterium, which separates its two fundamental metabolic processes (photosynthesis and nitrogen fixation) by time rather than place [3]. In complex organisms such as humans, every cell has its own circadian clock. The cellular circadian rhythm is generated via a molecular network of transcriptional-translational feedback loops, with one cycle taking approximately $24 \mathrm{~h}$ to complete [4]. In short, the Circadian Locomotor Output Cycles Kaput (CLOCK) and Brain And Muscle ARNT-Like 1 (BMAL1) genes encode a heterodimeric transcription factor known as CLOCK/ BMAL1 that activates E-box promoter containing genes, including the Period (PER1 and PER2) and Cryptochrome (CRY1 and CRY2) core clock genes and a variety of clockcontrolled genes (CCG) that couple the circadian oscillator to physiological and metabolic pathways. Once formed, PER/CRY protein complexes translocate to the nucleus where they inhibit CLOCK/BMAL1-mediated transcription of E-box genes, including their own [5]. Between 5 and $20 \%$ of all gene transcription in mammalian cells is controlled by this molecular oscillator depending on tissue type [6]. The oscillating transcriptome directly influences most biological pathways, ultimately shaping measurable indices such as body temperature, brain wave activity, cardiovascular and respiratory functions, coagulation and immunity [7].

\section{Keeping time}

Coordination of mammalian circadian timekeeping involves an integrated system composed of a central clock in the suprachiasmatic nucleus (SCN) of the hypothalamus, and peripheral clocks in virtually all other cells and tissues. The coordinated integration of central and peripheral molecular clocks ensures that functions in different tissues occur at an appropriate time of day, such as sleeping at night and metabolising ingested nutrients during the day in the case of diurnal animals. Without these molecular clocks, there would be no temporal framework for daily processes. Although circadian clocks continue to tick indefinitely, they require careful adjusting to keep in time. The central clock in the SCN fulfils a key role in this, as it integrates input from external cues, known as Zeitgebers, to synchronise with the planetary light/dark cycle. Whereas light, perceived through the eye, is the strongest Zeitgeber for daily clock resetting (photoentrainment), other cues include temperature, feeding, exercise and social interaction. In turn, the SCN maintains synchrony of peripheral clocks through humoral and neural stimuli. Resetting the circadian clocks to alterations in Zeitgebers scheduling takes time [8] and sudden environmental changes result in cellular rhythms being temporarily out of step with demands imposed by the environment (external desynchronisation). This phase shift is experienced as jet lag when we rapidly cross longitudes and it takes approximately 1 day to adapt to each hour time zone crossed. Clocks in different tissues adapt to disturbance at different rates, leading to internal desynchrony, like the individual instruments of an orchestra playing independently [9]. The hormone melatonin appears to play a role in both external and internal synchronisation. Its secretion from the pineal gland is inhibited by bright light (detected by non-visual photosensitive retinal ganglion cells), hence circulating melatonin levels are very low during the day [10]. Melatonin was previously thought to regulate the sleep/wake cycle, but its secretion follows a similar pattern in nocturnally active animals (i.e. increasing melatonin levels at the beginning of the dark period) and may be more accurately considered the "hormone of the dark".

\section{Chronotypes}

Whilst most humans follow a pattern of daytime wakefulness and night-time sleeping, there is natural variation in preferred time to wake and sleep. Chronotype is the behavioural expression of the set point of an individual's circadian rhythm. It describes their sleep-wake cycle in relation to time, and the two ends of the chronotype spectrum are called "morningness" and "eveningness". Morningness is characterised by early-morning waking, with mental and physical performance peaking in the first half of the day, and going to sleep relatively early; eveningness is the opposite. Chronotype can be determined by questionnaires such as the Munich Chronotype Questionnaire and the Horne-Ostberg Morningness-Eveningness Score [11]. A comprehensive and well-controlled study demonstrated that questionnaires such as these closely correlate to dim-light melatonin onset time, probably the most reliable measure of central circadian timing in humans [12]. There is a strong genetic component underlying this 
phenotype [13] and ignoring its influence is known to be detrimental to performance [14]. The eveningness chronotype has been associated with a predisposition to diabetes, metabolic syndrome, high body mass index and sarcopenia, as well as depressive disorders [15-17]. Knowledge of a patient's chronotype may be useful not just in the assessment of disease risk, but also in tailoring the timing of Zeitgebers such as light, food, exercise and sleep in order to preserve their natural circadian rhythm and optimise their biological function.

\section{Chronopathology}

Circadian rhythm disruption can be genetic or acquired, and its impact extends far beyond the fleeting symptoms of jet lag (Table 1), reflecting the range of functions which follow a circadian rhythm. Chronic circadian rhythm disruption has been linked with diverse pathologies, from metabolic disorders, obesity, diabetes, cardiovascular disease and cancer [18-21]. Genetic disruption results from mutations of the clock genes responsible for generating the cellular circadian rhythm. Such mutations result in a spectrum of sleep pattern disorders [22]. Given that clock genes regulate cell proliferation, metabolism, DNA repair and apoptosis, it is of no surprise that polymorphisms in these genes (including PER1 and PER2) have been associated with cancer in both mouse models and humans [23]. CLOCK gene mutations have been implicated in the development of obesity in humans and may play a key role in metabolic syndrome, type 2 diabetes and cardiovascular disease [24, 25]. Alterations within clock genes are also related to alcohol consumption [26] and recreational drug rewarding in animal models [27], indicating the far-reaching consequences of disruption to this fundamental regulatory system.

\section{Environmental clock disruption}

Living out of phase with one's body clock will also induce circadian dysrhythmia, and has also been shown to result in pathology [28]. Night shifts create a complete inversion

Table 1 Consequences of 'wrong thing-wrong time' leading to circadian desynchronisation in critically ill patients

\begin{tabular}{ll}
\hline Circadian misalignment & Clinical outcome \\
\hline Sleep-wake inversion & Sleep loss [113] \\
& Delirium [114] \\
& Poor compliance with physiotherapy \\
& and rehabilitation [115] \\
Continuous feeding at night time & Glucose intolerance [64] \\
& Dyslipidaemia [72] \\
& Metabolic dysfunction [71] \\
& Impaired wound healing [101] \\
Invasive interventions at night & \\
\hline
\end{tabular}

of the sleep-wake cycle, analogous to travelling across 12 time zones. Night shift workers have been found to have higher rates of a number of behavioural and health-related morbidities [29] including sleep disorders, obesity [30], metabolic syndrome [31] and cancer [32, 33]. Sleep restriction also disrupts the circadian rhythm and has a profound effect on metabolic control in healthy volunteer subjects [34]. We are currently facing an epidemic of environmental circadian rhythm disturbance, as modern work and social schedules forces people to live contrary to their chronotype (social jet lag) [35].

\section{Circadian dysrhythmia in critically ill patients}

Critically ill patients are particularly susceptible to circadian disruption (dysrhythmia) due to mistiming, or total loss, of sensory cues disturbing the master regulation within the environment of the intensive care unit, and/or pathology affecting the peripheral clock mechanism at a cellular level. The latter phenomenon is imperfectly understood, but may relate to the inflammatory response, with septic patients seen to have abnormal patterns of melatonin secretion relative to non-septic ventilated patients [36]. The cellular effect outlasts the septic insult, with animal models of sepsis demonstrating rhythm disturbances for weeks after the insult [37], findings mirrored in human survivors of sepsis even after discharge from the intensive care unit. Rhythmicity can be affected in different ways, leading to a loss of amplitude, asynchronous timing or degradation to a completely chaotic pattern [38]. The clinical consequences of this aspect of critical illness are thought to be manifold but may have been neglected in the past due to the more obvious and immediately life-threatening features of physiological instability. The two most obvious manifestations of circadian dysrhythmia on the intensive care unit are the two complex and interrelated phenomena of sleep disturbance and delirium (Fig. 1). Sleep disruption

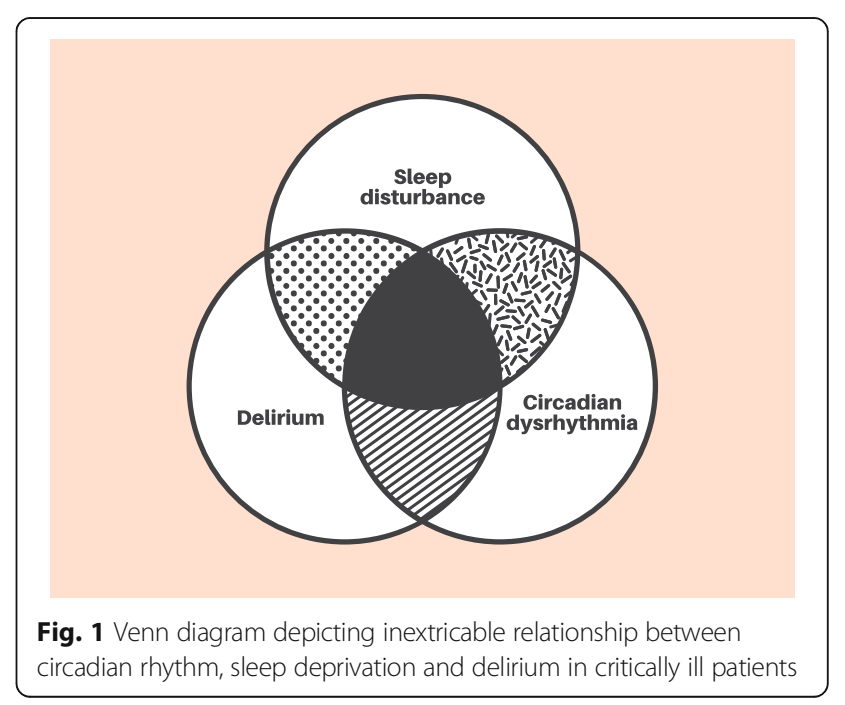


is one of the commonest afflictions reported by survivors of critical illness [39]. It manifests as fragmentation and disruption of sleep architecture [40], and a displacement of the greater proportion of sleep to the daytime [41]. Disturbed sleep is not only a manifestation of circadian dysthymia, but also a driver of further disarray in peripheral clocks [42], creating a vicious circle of disruption. Of the many downstream effects of sleep disruption, its impairment of the immune system has the most obvious ramifications for recovery from critical illness [43]. Evidence is also emerging that ICU delirium, a syndrome independently associated with increased mortality and long-term morbidity from critical illness [44], and affecting up to $80 \%$ of critically ill patients [45], is a clinical manifestation of circadian dysrhythmia (Fig. 1). Delirium is associated with a reduction in peak amplitude of a urinary metabolite of melatonin (6-sulfatoxymelatonin) [46]. Circadian disruption and sleep disturbance often precedes delirium, this temporal link suggesting a possible causal relationship [47].

Many of the effects of critical illness circadian dysrhythmia may not be detectable clinically, but the diverse ramifications we see in chronic circadian dysrhythmia, outlined earlier, highlight the degree to which cellular function in different tissues is affected, beyond the overt symptoms of sleep disturbance and cognitive impairment. For example, mitochondrial oxidative phosphorylation itself exhibits circadian oscillation $[48,49]$, disruption of which may result in mismatching of cellular energetics to demand. In patients with sepsis where cellular bioenergetic failure is already threatened [50] and drugs such as propofol suppress mitochondrial respiration [51], such a discrepancy may be catastrophic for cell function. We propose that "chronofitness", the correct alignment of peripheral and central clocks, should be a new target in the management of critical illness. The first step will be to identify and address the modifiable risk factors associated with the disruption of circadian rhythms in critically ill patients (Table 2), and implement strategies to prevent such disruption. Here we outline the rationale and evidence for a number of chronobiological strategies to improve outcome in critically ill patients.

\section{The intensive care unit environment}

Inside the intensive care unit, the usual schedule of Zeitgebers is obliterated. In the outside world, the variation between light and darkness ranges from $0.0001 \mathrm{~lx}$ on a moonless night to $0.25 \mathrm{~lx}$ during a full moon, $1000 \mathrm{~lx}$ on the most overcast day and 130,000 lx in brightest sunshine. At night, artificial light leaches into patient areas from many sources - room and corridor lights, the glare from monitors and torches used to measure pupil size (leading to mean night-time illumination of $10 \mathrm{~lx}$ in one study [52]) - whilst during the day indoor illumination rarely reaches that of the outside world even on an overcast
Table 2 Suggested chronobiological approaches to preserve circadian rhythms on the intensive care unit (ICU)

\begin{tabular}{|c|c|}
\hline Zeitgeber & Ideal ICU environment \\
\hline Light & $\begin{array}{l}\text { - Bright-light daylight hours }(>1000 \mathrm{~lx}) \\
\text { - Minimise light pollution at night }(<1 \mathrm{~lx}, \\
\text { consider) } \\
\text { - Eye masks at night }\end{array}$ \\
\hline Feeding & $\begin{array}{l}\text { - Intermittent daytime feeding aligned to } \\
\text { usual meal times } \\
\text { - Avoid continuous and overnight feeding }\end{array}$ \\
\hline Temperature & $\begin{array}{l}\text { - Warmer environment during the day and } \\
\text { cooler at night }\end{array}$ \\
\hline $\begin{array}{l}\text { Exercise } \\
\text { rehabilitation }\end{array}$ & $\begin{array}{l}\text { - Similar time each day } \\
\text { - Take patient chronotype into consideration } \\
\text { when planning schedule }\end{array}$ \\
\hline Noise & $\begin{array}{l}\text { - Minimise noise during the night time } \\
\text { - Ear plugs at night }\end{array}$ \\
\hline $\begin{array}{l}\text { Medical and nursing } \\
\text { interventions }\end{array}$ & $\begin{array}{l}\text { - Minimise at night and cohort together } \\
\text { - For non-sedated patients, allow patients to sleep } \\
\text { according to their natural schedule, rather than a } \\
\text { staff-based schedule }\end{array}$ \\
\hline Sedative drugs & $\begin{array}{l}\text { - Minimise use through regular review and avoid } \\
\text { "sleeping tablets" } \\
\text { - Consider melatonin (up to } 5 \mathrm{mg} \text { ) at } 0900 \mathrm{~h} \text { as } \\
\text { circadian preserving sleep aide } \\
\text { - When possible, give drugs at the time of day } \\
\text { least disturbing to circadian rhythms }\end{array}$ \\
\hline
\end{tabular}

day (mean daytime illumination $158 \mathrm{~lx}$ [52]). Excessive night-time light suppresses the release of melatonin, a key molecule orchestrating circadian rhythmicity in different tissues [53], and circadian disruption can be seen at a cellular level when cells are exposed to constant light [54]. Animal models of critical illness have demonstrated worse outcomes in the presence of circadian disturbance experimentally induced by constant exposure to light [55]. Imposing a light/dark cycle in a neonatal ICU accelerated body weight gain and shortened time to discharge in preterm infants [56]. "Chronofriendly" ICUs should aim to emulate normal day-time illumination levels with large windows, sufficient artificial lighting and perhaps incorporating blue-enhanced lighting in refurbishments and new builds [57]. A recent review summarised a number of randomised controlled trials in which morning bright-light therapy reduced delirium or improved sleep in acutely ill patients [58]. In a study published after this review, light therapy did not reduce the incidence of delirium in the critically ill and it is possible that it was less effective during early critical illness when patients were heavily sedated [59]. At night, providing sufficient light to perform critical tasks safely must be balanced against the negative effects of interruption of the patient's light/dark cycle. Where possible, night light should be minimised or the patient's eyes protected using eye masks. The use of lights and monitors that emit red rather than blue light at night may blunt inhibition of melatonin 
secretion [60]. Standards for morning light intensity during the day and night using luxmeters could be initiated.

Excessive night-time noise leads to sleep deprivation [61]. Noise reduction can be achieved by staff behaviour modification and the use of ear plugs in patients; the latter showing promising signs of being able to reduce ICU delirium [61]. Measurement of sound levels on ICU may help staff to understand which aspects of patient care create the most noise and facilitate the development of local guidelines to help minimise environmental noise pollution [62]. Other disturbances such as automated non-invasive blood pressure measurement, physical examination, turning and washing should be rationalised and cohorted at night, which as part of a bundle of interventions has been shown to improve sleep in the critically ill [63].

\section{Feeding}

The consumption of food is probably the most powerful Zeitgeber for peripheral clocks. Most mammals do not eat at night and enter a period of natural fasting, during which time they switch from using primarily glucose as a fuel source to ketone bodies [64]. Yet it remains common practice to feed critically ill adults continuously, whether via the enteral or parenteral route. Time-restricted feeding is a well-described intervention that has a profound effect on the circadian rhythm and may be a powerful tool in the prevention of metabolic disorders [65, 66]. Much of the benefit seen in animal models exploring this line of work appears to relate to the maintenance or entrainment of the circadian rhythm [67]. Numerous animal model studies have demonstrated that changes to normal feeding schedules have significant metabolic consequences [68], including reduction in the amplitude and an alteration of phase in hepatic metabolite levels [69]. Daytime feeding in nocturnally active mice shifted the liver clock by $180^{\circ}$ and resulted in significantly decreased survival rates in a sepsis model, in comparison to mice fed at night [70]. Eating out of phase with the SCN rhythm destroys the normal relationship between this central timekeeper and the peripheral clocks, and the resulting conflict manifests as gastrointestinal and metabolic disease [71]. This has been proposed as a mechanism for the increased incidence of obesity and metabolic disorders in shift workers [72]. A further interesting twist is the bidirectional circadian relationship between the gut microbiome and its host [73], with the circadian rhythm of one influencing the other. Whilst studies have been undertaken to look at outcome differences between bolus versus continuous feeding in subsets of critically ill patients [74, 75], they did not consider circadian factors in their design. A recent and eloquent personal perspective on this topic by Paul Marik [76] highlighted that providing continuous protein or amino acid supplementation limits skeletal muscle protein synthesis whilst intermittent feeding promotes it. His article concludes by stating: "Continuous tube feeding is unphysiological and likely harmful and should be abandoned" [76].

\section{Physical activity}

Loss of daytime physical activity may be absolute in severe critical illness, as the result of sedation, paralysis, muscle weakness or critical illness polyneuropathy or myopathy. Posture on the ICU is predominantly supine, rather than upright, for much of the day. There is a chronobiological argument for incorporating early basic patient mobilisation, even passively, through physiotherapy, at the times relevant to that patient. Some have suggested that early mobilisation may contribute to circadian health, and early mobilisation has been suggested as being an essential component of any strategy to reduce delirium in the critically ill [77]. Individual chronotyping (through questioning relatives) may be especially valuable here; perhaps increases in compliance with valuable physiotherapy could be achieved in awake patients, by targeting their morningness or eveningness.

\section{Sedation}

Sedatives can be a necessary evil in critical care medicine, but their side-effect profile may extend beyond our current awareness [78]. Administration of sedatives to the critically ill worsens sleep patterns and delirium, and drives circadian dysrhythmia [79, 80], with desynchronisation of the rhythmical secretion of melatonin demonstrated in sedated, mechanically ventilated patients [81]. Benzodiazepines appear to be the greatest offenders in this group [81, 82]. When possible, minimising the use of sedative drugs is likely to be beneficial for critically patients [78], and will require the optimisation of analgesia. In particular, it is advisable to avoid the knee-jerk reaction to treat sleep disturbance with sedative medications, which do not provide the active biological functions of sleep, and exacerbate sleep disturbance and delirium in the critically ill.

\section{Implementing an integrated "chronobundle" to entrain faltering circadian rhythms in the critically ill} There is a biological rationale for keeping Zeitgeibers at their "expected" time to minimise harm from desynchronisation of peripheral and central clocks (Fig. 2). On the basis of the mechanisms and evidence from human and animal studies outlined, we propose a "chronobundle" to promote chronofitness as part of daily management of critically ill patients, summarised in Fig. 2. There is evidence that interventions may have greater benefit in combination, with a systematic review of multicomponent strategies based on environmental modifications demonstrating decreases in delirium incidence (odds ratio 0.47) [83]. Some chronobundle elements used to improve sleep 


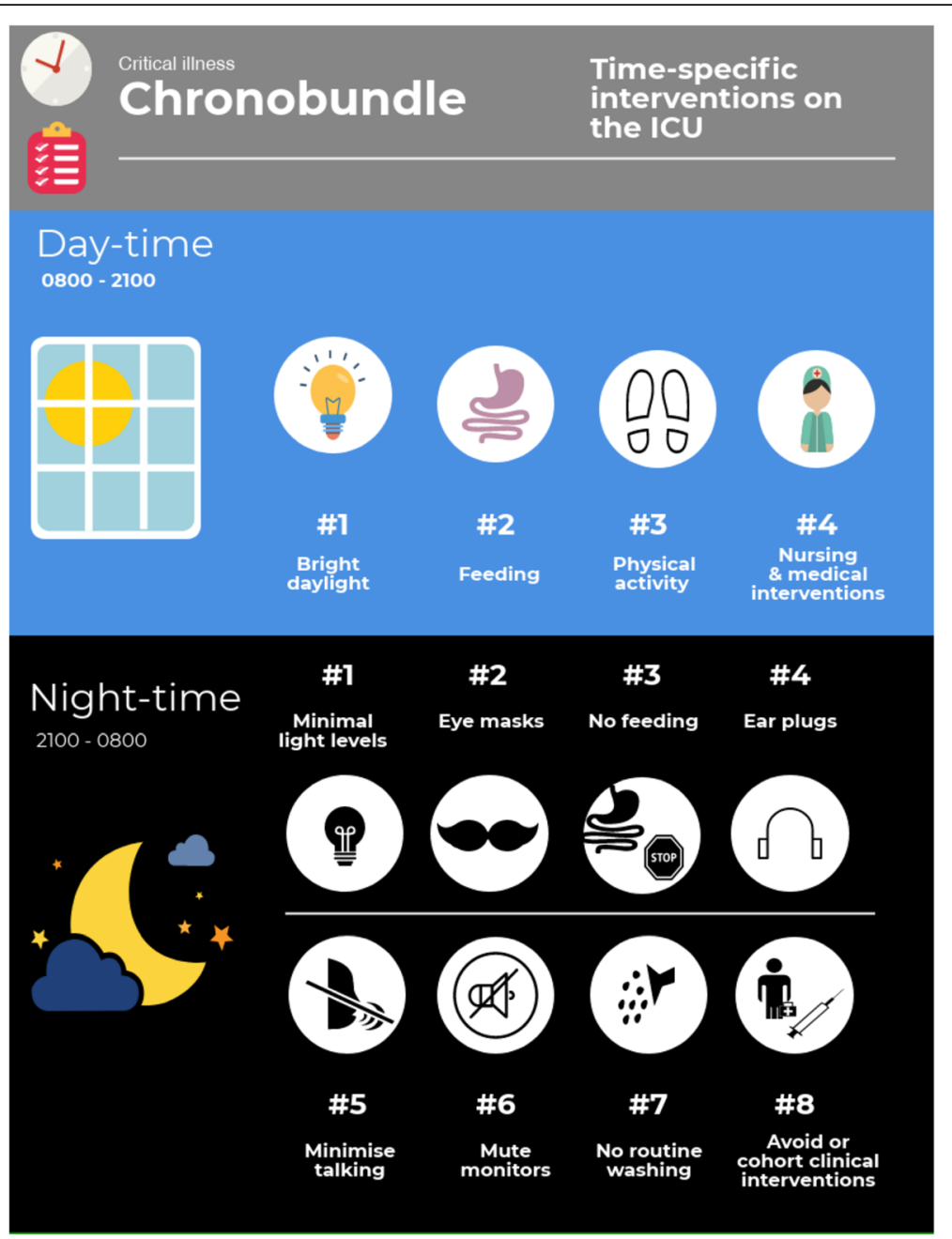

Fig. 2 Schematic of a suggested "chronobundle" of care for critically ill patients. Attempt to maintain normal circadian pattern of activity even when patients are critically ill through simple multimodal scheduling and interventions. ICU intensive care unit

in critically ill patients such as the use of ear plugs and eye masks have demonstrated benefit [84] and influenced circulating melatonin levels in a simulated critical care setting [85]. Individualising Zeitgeber timing according to a patient's chronotype may further improve the impact of such interventions. This chronotype-specific approach has been explored as a performance enhancing tactic in both athletes [14] and college students [86]. Information regarding chronotype could be sought from close relatives and friends, and questionnaires exist to quantify responses from specific questions [11].

\section{Current challenges and future perspectives on the monitoring of circadian rhythms in the ICU}

The volume of literature devoted to understanding the impact of circadian disruption on critically ill patients is small. In a setting in which heterogeneity of disease and treatments is sizable, linking cause with effect is challenging. Unless a patient's circadian rhythm is accurately determined, it is impossible to determine how it may influence clinical outcomes. Currently, this is not possible outside the setting of complex research projects. Improving chronofitness in critically ill patients will require the ability to monitor circadian rhythms in the clinical setting. Measuring circadian rhythms, in real time and in different tissues, will be essential for identification of circadian dysrhythmias and for assessing the effect of interventions to improve clock alignment. As every physiological function has a circadian oscillation, each proffers a potential biomarker for tracking rhythmicity. In healthy volunteers and ambulatory patients, circadian rhythms can be mapped using activity monitors [87]. However, this has been shown to overestimate sleep time compared to polysomnography in the critically ill [88], presumably as actigraphy is unable to distinguish between true sleep and motionless wakefulness. It is usual to collect hourly physiological information from critically ill patients and the use of electronic data systems allows 
greater recording frequency of measurement variables providing a rich dataset of biorhythms. Although clinicians appreciate the importance of trends over time, we lack the terminology for describing or quantifying biological rhythms, or changes in their characteristics. Clinicians need to become more familiar with normal patterns of circadian oscillation in key physiological functions (e.g. the nadir of temperature, blood pressure and heart rate in the early hours of the morning), and to develop pattern recognition strategies to identify critical circadian disruption, similar to the manner in which we identify a rhythm disturbance in an electrocardiogram. A more sophisticated approach would require quantitative analysis of rhythms, perhaps via software able to process real-time physiological data, to identify: timing of peaks (or troughs) enabling phase shift determination; amplitude of variation, from peak to trough; and the consistency of the rhythm over days. Techniques to achieve this are commonly used in the experimental setting [89], but have yet to transfer across to clinical practice. Medical education in the future may need to provide clinicians with the mathematical competence to handle more complex data relating to biological rhythms, or to use algorithms for their interpretation. Attempts have been made to plot circadian rhythms using biomarkers including serum melatonin [90] and cortisol levels [91], urinary melatonin metabolites [36, 81], sleep-wake cycles using polysomnography [41] and hourly temperature and urine outputs [92]. A multitude of hormones related to metabolism levels are under circadian control such as insulin, ghrelin, leptin and growth hormone [93, 94]; these too could be used to help determine circadian profiles in the critically ill in a study setting [95]. Finding the optimum tool to monitor critically ill patients therefore remains a key to research progress in this area.

\section{Chronotherapeutics: delivering the right treatment at the right time}

The ability to map an individual's circadian rhythm conveys the potential ability to personalise critical care. For example, given the typical fluctuations of physiological variables throughout the 24 -h period in health, we could evaluate the benefit of different physiological targets for day and night.

Monitoring circadian rhythms will be essential for the implementation of "chronotherapeutics", the timing of an intervention or administration of a drug at the time of day where it is likely to have the optimum effect. Pharmacodynamics and pharmacokinetics show that predictable circadian oscillations manner [96, 97]. Whilst we tend to prescribe certain drugs at certain times of the day, it is generally without consideration of how each drug's therapeutic profile may be affected by the time of day. Absorption, hepatic metabolism and renal excretion all follow a circadian rhythm [97], as do the biological processes on which drugs act. Chronotherapeutic strategies have proved beneficial in cancer treatment [98] where circadian-timed chemotherapy may improve outcomes. Optimising the timing of drugs with a narrow therapeutic index and significant circadian fluctuation, such as antibiotics, steroids and anticoagulants, could lead to significant clinical benefit from improvements in efficacy and minimisation of toxicity [97, 99]. Benzodiazepines phase-shift the clock according to the time of day at which they are administered [100], and thus the circadian disruption effect could be minimised by administering the drug at the correct time of day relative to the patient's circadian phase.

Our defence from trauma and its accompanying stress response is also dependent on the time of day. Recently, it was reported that elective cardiac operations performed in the afternoon were associated with improved patient outcomes, which the authors related to changes in the oscillating gene expression of the nuclear receptor Rev-Erbo [101]. The time-of-day factor has also been implicated in the efficacy of wound healing in patients, with burn injuries incurred during the day healing up to $60 \%$ faster than those sustained at night, which may be explained by temporal patterns of fibroblast activity in a mouse model [102].

These preliminary data point towards the improvements in outcome that may be achieved by greater understanding of the temporal nature of healing responses, and highlight the need to develop a comprehensive temporal blueprint for different tissue rhythms to allow clinicians to plan interventions to take advantage of the predictable cycling of human immune and healing responses. Such a blueprint will have to take account of differing chronotypes.

\section{Pharmacological adjustment of circadian dysrhythmia}

Melatonin is thought to align the phases of peripheral clocks in different tissues with that of the central SCN [103]. In humans, melatonin is released from the pineal gland, beginning from 2100 to $2300 \mathrm{~h}$, peaking between 0100 and $0300 \mathrm{~h}$, and reaching its nadir between 0700 and $0900 \mathrm{~h}$ (virtually a mirror image of cortisol release). Taken enterally, melatonin improves the quality of sleep [104], and there is some evidence for its effectiveness in treating jet lag [105]. A number of randomised controlled trials have investigated melatonin and melatonin receptor antagonists in critically ill patients [106]. They have shown initial success in improving sleep quality and reducing delirium in some subsets of critically ill patients [107-110]. However, no large-scale randomised controlled trials have been conducted in this area and this is clearly a priority area for future research.

In the future we may be able to target the molecular clockwork itself with pharmacological agents. Synthetic ligands are currently under investigation for Rev-Erb 
( $\alpha$ and $\beta$ ) and retinoic acid receptor-related orphan receptors [111]. They have a particular potential for the treatment of metabolic syndrome [112], but as this field advances the scope of synthetic ligands may widen to include more fields of medicine, including critical care.

\section{Conclusions}

Circadian rhythms are currently low on the list of physiological priorities during ICU ward rounds. We have argued that recognition of the influence of this universally important system, and adoption of chronobiological strategies, has the potential to improve patient outcomes [38]. Circadian rhythmicity represents one of the oldest survival strategies, present in all life-forms on earth. Traditional treatment of critical illness ignores this fundamental physiological function, with many of our interventions inadvertently obliterating it. A new chronobiological approach to patient care would involve: education for clinical staff, regarding the recognition of circadian rhythms and dysrhythmias; development of technology to measure circadian rhythms quantitatively in critically ill patients; and investing in multicomponent strategies (chronobundles) to preserve or restore the synchronicity, phase and amplitude of circadian rhythms. For the latter, pharmacological solutions remain untested, but the non-pharmacological components of these bundles are simple and logical interventions of relatively low cost. Any chronotherapy will ultimately need to take account of time of day and individual patient chronotype.

\section{Authors' contributions}

HM, GTJvdH, IR and DM all conceived the idea for the review article. HM, GTJvdH, IR and DM all wrote the article. HM, GTJvdH, IR and DM all revised the article. All authors read and approved the final manuscript.

\section{Competing interests}

The authors declare that they have no competing interests.

\section{Publisher's Note}

Springer Nature remains neutral with regard to jurisdictional claims in published maps and institutional affiliations.

\section{Author details \\ ${ }^{1}$ University College London Centre for Altitude Space and Extreme Environment Medicine, University College London Hospitals NIHR Biomedical Research Centre, Institute of Sport and Exercise Health, First Floor, 170 Tottenham Court Road, London W1T 7HA, UK. ${ }^{2}$ Department of Molecular Genetics, Erasmus University Medical Center, Wytemaweg 80, 3015 CN Rotterdam, the Netherlands. ${ }^{3}$ Division of Neonatology, Department of Paediatrics, Erasmus Medical Center, Rotterdam, the Netherlands. ${ }^{4}$ Critical Care Unit, Royal Free Hospital, Pond Street, London NW3 2QG, UK.}

\section{Received: 23 December 2017 Accepted: 13 April 2018}

Published online: 11 May 2018

\section{References}

1. Gotts JE, Matthay MA. Sepsis: pathophysiology and clinical management BMJ. 2016;353:11585.

2. Holst LB, Haase N, Wetterslev J, et al. Lower versus higher hemoglobin threshold for transfusion in septic shock. N Engl J Med. 2014;371:1381-91.
3. Hall JC, Rosbash M. Oscillating molecules and how they move circadian clocks across evolutionary boundaries. Proc Natl Acad Sci U S A. 1993;90:5382-3.

4. Ko CH, Takahashi JS. Molecular components of the mammalian circadian clock. Hum Mol Genet. 2006;15 Spec No 2:R271-7.

5. Mohawk JA, Green CB, Takahashi JS. Central and peripheral circadian clocks in mammals. Annu Rev Neurosci. 2012;35:445-62.

6. Takahashi JS. Transcriptional architecture of the mammalian circadian clock. Nat Rev Genet. 2017:18:164-79.

7. Chan MC, Spieth PM, Quinn K, Parotto M, Zhang H, Slutsky AS. Circadian rhythms: from basic mechanisms to the intensive care unit. Crit Care Med. 2012:40:246-53.

8. Weaver DR. The suprachiasmatic nucleus: a 25-year retrospective. J Biol Rhythm. 1998;13:100-12.

9. Yamazaki S, Numano R, Abe M, et al. Resetting central and peripheral circadian oscillators in transgenic rats. Science. 2000;288:682-5.

10. Arendt J. Melatonin and the pineal gland: influence on mammalian seasonal and circadian physiology. Rev Reprod. 1998;3:13-22.

11. Zavada A, Gordijn MC, Beersma DG, Daan S, Roenneberg T. Comparison of the Munich Chronotype Questionnaire with the Horne-Ostberg's Morningness-Eveningness Score. Chronobiol Int. 2005;22:267-78.

12. Kantermann $\mathrm{T}$, Sung $\mathrm{H}$, Burgess HJ. Comparing the MorningnessEveningness Questionnaire and Munich ChronoType Questionnaire to the Dim Light Melatonin Onset[letter]. J Biol Rhythm. 2015;30(5):449-53.

13. Kalmbach DA, Schneider LD, Cheung J, et al. Genetic basis of chronotype in humans: insights from three landmark gwas. Sleep. 2017;40(2).

14. Facer-Childs E, Brandstaetter R. The impact of circadian phenotype and time since awakening on diurnal performance in athletes. Curr Biol. 2015;25:518-22.

15. Arora T, Taheri S. Associations among late chronotype, body mass index and dietary behaviors in young adolescents. Int J Obes. 2015;39:39-44.

16. $\mathrm{Yu} J \mathrm{H}$, Yun $\mathrm{CH}, \mathrm{Ahn} \mathrm{JH}$, et al. Evening chronotype is associated with metabolic disorders and body composition in middle-aged adults. J Clin Endocrinol Metab. 2015;100:1494-502.

17. Lester D. Morningness-eveningness, current depression, and past suicidality. Psychol Rep. 2015;116:331-6.

18. Lamia KA. Ticking time bombs: connections between circadian clocks and cancer. F1000Res. 2017:6:1910.

19. Young ME, Bray MS. Potential role for peripheral circadian clock dyssynchrony in the pathogenesis of cardiovascular dysfunction. Sleep Med. 2007:8:656-67.

20. Roenneberg T, Allebrandt KV, Merrow M, Vetter C. Social jetlag and obesity. Curr Biol. 2012;22:939-43.

21. Wong PM, Hasler BP, Kamarck TW, Muldoon MF, Manuck SB. Social jetlag, chronotype, and cardiometabolic risk. J Clin Endocrinol Metab. 2015;100:4612-20.

22. Jones CR, Campbell SS, Zone SE, et al. Familial advanced sleep-phase syndrome: a short-period circadian rhythm variant in humans. Nat Med. 1999:5:1062-5

23. Wood PA, Yang X, Hrushesky WJ. Clock genes and cancer. Integr Cancer Ther. 2009;8:303-8

24. Gomez-Abellan P, Hernandez-Morante JJ, Lujan JA, Madrid JA, Garaulet M. Clock genes are implicated in the human metabolic syndrome. Int J Obes. 2008:32:121-8.

25. Scott EM, Carter AM, Grant PJ. Association between polymorphisms in the Clock gene, obesity and the metabolic syndrome in man. Int J Obes. 2008; 32:658-62.

26. Spanagel R, Rosenwasser AM, Schumann G, Sarkar DK. Alcohol consumption and the body's biological clock. Alcohol Clin Exp Res. 2005;29:1550-7.

27. McClung CA, Sidiropoulou K, Vitaterna $M$, et al. Regulation of dopaminergic transmission and cocaine reward by the Clock gene. Proc Natl Acad Sci U S A. 2005;102:9377-81.

28. Lévi F, Dugué PA, Innominato $P$, et al. Wrist actimetry circadian rhythm as a robust predictor of colorectal cancer patients survival. Chronobiol Int. 2014; 31:891-900.

29. Drake CL, Roehrs T, Richardson G, Walsh JK, Roth T. Shift work sleep disorder: prevalence and consequences beyond that of symptomatic day workers. Sleep. 2004;27:1453-62.

30. Ekmekcioglu C, Touitou Y. Chronobiological aspects of food intake and metabolism and their relevance on energy balance and weight regulation. Obes Rev. 2011;12:14-25.

31. De Bacquer D, Van Risseghem M, Clays E, Kittel F, De Backer G, Braeckman L. Rotating shift work and the metabolic syndrome: a prospective study. Int J Epidemiol. 2009;38:848-54. 
32. Davis S, Mirick DK, Stevens RG. Night shift work, light at night, and risk of breast cancer. J Natl Cancer Inst. 2001;93:1557-62.

33. Viswanathan AN, Hankinson SE, Schernhammer ES. Night shift work and the risk of endometrial cancer. Cancer Res. 2007;67:10618-22.

34. Buxton OM, Cain SW, O'Connor SP, et al. Adverse metabolic consequences in humans of prolonged sleep restriction combined with circadian disruption. Sci Transl Med. 2012;4:129ra43.

35. Wittmann M, Dinich J, Merrow M, Roenneberg T. Social jetlag: misalignment of biological and social time. Chronobiol Int. 2006;23:497-509.

36. Mundigler $G$, Delle-Karth $G$, Koreny $M$, et al. Impaired circadian rhythm of melatonin secretion in sedated critically ill patients with severe sepsis. Crit Care Med. 2002;30:536-40.

37. O'Callaghan EK, Anderson ST, Moynagh PN, Coogan AN. Long-lasting effects of sepsis on circadian rhythms in the mouse. PLoS One. 2012;7:e47087.

38. McKenna HT, Reiss IKM, Martin DS. The significance of circadian rhythms and dysrhythmias in critical illness. JICS. 2017;2:121-9.

39. Rotondi A, Chelluri L, Sirio $C$, et al. Patients' recollections of stressful experiences while receiving prolonged mechanical ventilation in an intensive care unit. Crit Care Med. 2002;30:746-52.

40. Weinhouse GL, Schwab RJ, Watson PL, et al. Bench-to-bedside review: delirium in ICU patients_-importance of sleep deprivation. Crit Care. 2009; $13: 234$.

41. Freedman NS, Gazendam J, Levan L, Pack Al, Schwab RJ. Abnormal sleep/ wake cycles and the effect of environmental noise on sleep disruption in the intensive care unit. Am J Respir Crit Care Med. 2001;163:451-7.

42. Wright KP, Gronfier C, Duffy JF, Czeisler CA. Intrinsic period and light intensity determine the phase relationship between melatonin and sleep in humans. J Biol Rhythm. 2005;20:168-77.

43. Born J, Lange T, Hansen K, Mölle M, Fehm HL. Effects of sleep and circadian rhythm on human circulating immune cells. J Immunol. 1997;158:4454-64.

44. Ely EW, Shintani A, Truman B, et al. Delirium as a predictor of mortality in mechanically ventilated patients in the intensive care unit. JAMA. 2004;291: 1753-62.

45. Raviglione MC, Snider DEJ, Kochi A. Global epidemiology of tuberculosis. Morbidity and mortality of a worldwide epidemic. JAMA. 1995;273:220-6.

46. Dessap AM, Roche-Campo F, Launay JM, et al. Delirium and circadian rhythm of melatonin during weaning from mechanical ventilation: an ancillary study of a weaning trial. Chest. 2015;148:1231-41.

47. Eckle T. Delirium - a dysfunctional circadian rhythm. Int J Anesth Res. 2016; $4: 1-3$

48. van der Horst GT, Muijtjens M, Kobayashi K, et al. Mammalian Cry1 and Cry2 are essential for maintenance of circadian rhythms. Nature. 1999;398:627-30.

49. Peek CB, Affinati AH, Ramsey KM, et al. Circadian clock NAD+ cycle drives mitochondrial oxidative metabolism in mice. Science. 2013:342:1243417.

50. Brealey D, Brand M, Hargreaves I, et al. Association between mitochondrial dysfunction and severity and outcome of septic shock. Lancet. 2002;360:219-23.

51. Schenkman KA, Yan S. Propofol impairment of mitochondrial respiration in isolated perfused guinea pig hearts determined by reflectance spectroscopy. Crit Care Med. 2000;28:172-7.

52. Durrington HJ, Clark R, Greer R, et al. 'In a dark place, we find ourselves': light intensity in critical care units[letter]. Intensive Care Med Exp. 2017;5(1):9.

53. Lewy AJ, Wehr TA, Goodwin FK, Newsome DA, Markey SP. Light suppresses melatonin secretion in humans. Science. 1980;210:1267-9.

54. Ohta H, Yamazaki S, McMahon DG. Constant light desynchronizes mammalian clock neurons. Nat Neurosci. 2005:8:267-9.

55. Carlson DE, Chiu WC. The absence of circadian cues during recovery from sepsis modifies pituitary-adrenocortical function and impairs survival. Shock. 2008;29:127-32

56. Vásquez-Ruiz S, Maya-Barrios JA, Torres-Narváez P, et al. A light/dark cycle in the NICU accelerates body weight gain and shortens time to discharge in preterm infants. Early Hum Dev. 2014;90:535-40.

57. Holzman DC. What's in a color? The unique human health effects of blue light. Environ Health Perspect. 2010;118:A22-7.

58. Oldham MA, Lee HB, Desan PH. Circadian rhythm disruption in the critically ill: an opportunity for improving outcomes. Crit Care Med. 2016;44:207-17.

59. Simons KS, Laheij RJ, van den Boogaard M, et al. Dynamic light application therapy to reduce the incidence and duration of delirium in intensive-care patients: a randomised controlled trial. Lancet Respir Med. 2016;4:194-202.

60. Tosini G, Ferguson I, Tsubota K. Effects of blue light on the circadian system and eye physiology. Mol Vis. 2016;22:61-72.
61. Xie H, Kang J, Mills GH. Clinical review: The impact of noise on patients' sleep and the effectiveness of noise reduction strategies in intensive care units. Crit Care. 2009;13:208.

62. Elbaz M, Léger D, Sauvet F, et al. Sound level intensity severely disrupts sleep in ventilated ICU patients throughout a 24-h period: a preliminary $24-\mathrm{h}$ study of sleep stages and associated sound levels. Ann Intensive Care. 2017;7:25.

63. Patel J, Baldwin J, Bunting P, Laha S. The effect of a multicomponent multidisciplinary bundle of interventions on sleep and delirium in medical and surgical intensive care patients. Anaesthesia. 2014;69:540-9.

64. Longo VD, Panda S. Fasting, circadian rhythms, and time-restricted feeding in healthy lifespan. Cell Metab. 2016;23:1048-59.

65. Hatori M, Vollmers C, Zarrinpar A, et al. Time-restricted feeding without reducing caloric intake prevents metabolic diseases in mice fed a high-fat diet. Cell Metab. 2012;15:848-60.

66. Chaix A, Zarrinpar A, Miu P, Panda S. Time-restricted feeding is a preventative and therapeutic intervention against diverse nutritional challenges. Cell Metab. 2014;20:991-1005.

67. Stokkan KA, Yamazaki S, Tei H, Sakaki Y, Menaker M. Entrainment of the circadian clock in the liver by feeding. Science. 2001;291:490-3.

68. Asher G, Sassone-Corsi P. Time for food: the intimate interplay between nutrition, metabolism, and the circadian clock. Cell. 2015;161:84-92.

69. Adamovich Y, Rousso-Noori L, Zwighaft Z, et al. Circadian clocks and feeding time regulate the oscillations and levels of hepatic triglycerides. Cell Metab. 2014;19:319-30.

70. Oyama Y, Iwasaka H, Koga H, Shingu C, Matsumoto S, Noguchi T. Uncoupling of peripheral and master clock gene rhythms by reversed feeding leads to an exacerbated inflammatory response after polymicrobial sepsis in mice. Shock. 2014;41:214-21.

71. Bishehsari F, Levi F, Turek FW, Keshavarzian A. Circadian rhythms in gastrointestinal health and diseases. Gastroenterology. 2016;151:e1-5.

72. Broussard JL, Van Cauter E. Disturbances of sleep and circadian rhythms: novel risk factors for obesity. Curr Opin Endocrinol Diabetes Obes. 2016;23:353-9.

73. Rosselot AE, Hong Cl, Moore SR. Rhythm and bugs: circadian clocks, gut microbiota, and enteric infections. Curr Opin Gastroenterol. 2016;32:7-11.

74. MacLeod JB, Lefton J, Houghton D, et al. Prospective randomized control trial of intermittent versus continuous gastric feeds for critically ill trauma patients. J Trauma. 2007;63:57-61.

75. Rhoney DH, Parker D, Formea CM, Yap C, Coplin WM. Tolerability of bolus versus continuous gastric feeding in brain-injured patients. Neurol Res. 2002; 24:613-20.

76. Marik PE. Feeding critically ill patients the right "whey": thinking outside of the box. A personal view. Ann Intensive Care. 2015;5:51.

77. Davidson JE, Harvey MA, Bemis-Dougherty A, Smith JM, Hopkins RO. Implementation of the Pain, Agitation, and Delirium Clinical Practice Guidelines and promoting patient mobility to prevent post-intensive care syndrome. Crit Care Med. 2013;41:S136-45.

78. Reade MC, Finfer S. Sedation and delirium in the intensive care unit. N Engl J Med. 2014;370:444-54.

79. Kondili E, Alexopoulou C, Xirouchaki N, Georgopoulos D. Effects of propofol on sleep quality in mechanically ventilated critically ill patients: a physiological study. Intensive Care Med. 2012;38:1640-6.

80. Pandharipande P, Ely EW. Sedative and analgesic medications: risk factors for delirium and sleep disturbances in the critically ill. Crit Care Clin. 2006;22: 313-27. vii

81. Olofsson K, Alling C, Lundberg D, Malmros C. Abolished circadian rhythm of melatonin secretion in sedated and artificially ventilated intensive care patients. Acta Anaesthesiol Scand. 2004:48:679-84.

82. Pandharipande $P$, Shintani A, Peterson J, et al. Lorazepam is an independent risk factor for transitioning to delirium in intensive care unit patients. Anesthesiology. 2006;104:21-6.

83. Hshieh $\Pi$, Yue J, Oh $E$, et al. Effectiveness of multicomponent nonpharmacological delirium interventions: a meta-analysis. JAMA Intern Med. 2015:175:512-20

84. Scotto CJ, McClusky C, Spillan S, Kimmel J. Earplugs improve patients' subjective experience of sleep in critical care. Nurs Crit Care. 2009;14:180-4.

85. Hu RF, Jiang XY, Zeng YM, Chen XY, Zhang YH. Effects of earplugs and eye masks on nocturnal sleep, melatonin and cortisol in a simulated intensive care unit environment. Crit Care. 2010;14:R66.

86. Beşoluk S, Onder I, Deveci I. Morningness-eveningness preferences and academic achievement of university students. Chronobiol Int. 2011;28:118-25. 
87. Littner M, Kushida CA, Anderson WM, et al. Practice parameters for the role of actigraphy in the study of sleep and circadian rhythms: an update for 2002. Sleep. 2003;26:337-41.

88. Beecroft JM, Ward M, Younes M, Crombach S, Smith O, Hanly PJ. Sleep monitoring in the intensive care unit: comparison of nurse assessment, actigraphy and polysomnography. Intensive Care Med. 2008;34:2076-83.

89. Palesh O, Haitz K, Lévi F, et al. Relationship between subjective and actigraphy-measured sleep in 237 patients with metastatic colorectal cancer. Qual Life Res. 2017;26:2783-91.

90. Miyazaki T, Kuwano $\mathrm{H}$, Kato $\mathrm{H}$, et al. Correlation between serum melatonin circadian rhythm and intensive care unit psychosis after thoracic esophagectomy. Surgery. 2003;133:662-8.

91. Paul T, Lemmer B. Disturbance of circadian rhythms in analgosedated intensive care unit patients with and without craniocerebral injury. Chronobiol Int. 2007:24:45-61.

92. Nuttall GA, Kumar M, Murray MJ. No difference exists in the alteration of circadian rhythm between patients with and without intensive care unit psychosis. Crit Care Med. 1998;26:1351-5.

93. Huang W, Ramsey KM, Marcheva B, Bass J. Circadian rhythms, sleep, and metabolism. J Clin Invest. 2011;121:2133-41.

94. Hastings M, O'Neill JS, Maywood ES. Circadian clocks: regulators of endocrine and metabolic rhythms. J Endocrinol. 2007;195:187-98.

95. Bornstein SR, Licinio J, Tauchnitz R, et al. Plasma leptin levels are increased in survivors of acute sepsis: associated loss of diurnal rhythm, in cortisol and leptin secretion. J Clin Endocrinol Metab. 1998;83:280-3.

96. Lemmer B. The clinical relevance of chronopharmacology in therapeutics. Pharmacol Res. 1996;33:107-15

97. Dallmann R, Brown SA, Gachon F. Chronopharmacology: new insights and therapeutic implications. Annu Rev Pharmacol Toxicol. 2014;54:339-61.

98. Lévi F. Chronotherapeutics: the relevance of timing in cancer therapy. Cancer Causes Control. 2006;17:611-21.

99. Blunston MA, Yonovitz A, Woodahl EL, Smolensky MH. Gentamicin-induced ototoxicity and nephrotoxicity vary with circadian time of treatment and entail separate mechanisms. Chronobiol Int. 2015;32:1223-32.

100. Benedetti F, Pontiggia A, Bernasconi A, Colombo C, Florita M, Smeraldi E. Lormetazepam in depressive insomnia: new evidence of phase-response effects of benzodiazepines. Int Clin Psychopharmacol. 2004;19:311-7.

101. Montaigne D, Marechal X, Modine T, et al. Daytime variation of perioperative myocardial injury in cardiac surgery and its prevention by Rev-Erbalpha antagonism: a single-centre propensity-matched cohort study and a randomised study. Lancet. 2017;391:59-69.

102. Hoyle NP, Seinkmane E, Putker M, et al. Circadian actin dynamics drive rhythmic fibroblast mobilization during wound healing. Sci Transl Med. 2017;9(415).

103. Gandhi AV, Mosser EA, Oikonomou G, Prober DA. Melatonin is required for the circadian regulation of sleep. Neuron. 2015;85:1193-9.

104. Garfinkel D, Laudon M, Nof D, Zisapel N. Improvement of sleep quality in elderly people by controlled-release melatonin. Lancet. 1995;346:541-4.

105. Herxheimer A, Petrie KJ. Melatonin for the prevention and treatment of jet lag. Cochrane Database Syst Rev. 2001;(1):CD001520.

106. Mo Y, Scheer CE, Abdallah GT. Emerging role of melatonin and melatonin receptor agonists in sleep and delirium in intensive care unit patients. J Intensive Care Med. 2016:31:451-5.

107. Ibrahim MG, Bellomo R, Hart GK, et al. A double-blind placebo-controlled randomised pilot study of nocturnal melatonin in tracheostomised patients. Crit Care Resusc. 2006;8:187-91.

108. Bourne RS, Mills GH, Minelli C. Melatonin therapy to improve nocturnal sleep in critically ill patients: encouraging results from a small randomised controlled trial. Crit Care. 2008;12:R52.

109. Vijayakumar HN, Ramya K, Duggappa DR, et al. Effect of melatonin on duration of delirium in organophosphorus compound poisoning patients: a double-blind randomised placebo controlled trial. Indian J Anaesth. 2016;60: 814-20.

110. Bily B, Sabol F, Török $P$, Artemiou P, Bilecova-Rabajdova M, Kolarcik P. Influence of prophylactic melatonin administration on the incidence of early postoperative delirium in cardiac surgery patients. Anesteziol Intenzivni Med. 2015;26:319-27.

111. Kojetin DJ, Burris TP. REV-ERB and ROR nuclear receptors as drug targets. Nat Rev Drug Discov. 2014;13:197-216.
112. Marciano DP, Chang MR, Corzo CA, et al. The therapeutic potential of nuclear receptor modulators for treatment of metabolic disorders: PPARY, RORs, and Rev-erbs. Cell Metab. 2014;19:193-208.

113. Härmä M, Tenkanen $L$, Sjöblom T, Alikoski T, Heinsalmi P. Combined effects of shift work and life-style on the prevalence of insomnia, sleep deprivation and daytime sleepiness. Scand J Work Environ Health. 1998;24:300-7.

114. FitzGerald JM, O'Regan N, Adamis D, et al. Sleep-wake cycle disturbances in elderly acute general medical inpatients: longitudinal relationship to delirium and dementia. Alzheimers Dement (Amst). 2017;7:61-8.

115. Leditschke IA, Green M, Irvine J, Bissett B, Mitchell IA. What are the barriers to mobilizing intensive care patients. Cardiopulm Phys Ther J. 2012;23:26-9.

\section{Ready to submit your research? Choose BMC and benefit from:}

- fast, convenient online submission

- thorough peer review by experienced researchers in your field

- rapid publication on acceptance

- support for research data, including large and complex data types

- gold Open Access which fosters wider collaboration and increased citations

- maximum visibility for your research: over $100 \mathrm{M}$ website views per year

At BMC, research is always in progress.

Learn more biomedcentral.com/submissions 